\title{
COMENTARIO JURISPRUDENCIAL EN TORNO AL CÓMPUTO \\ DEL PLAZO DE PRESCRIPCIÓN EN PAGARÉS CON \\ CLÁUSULA DE ACELERACIÓN
}

\section{Humberto Carrasco Blanc ${ }^{*}$}

\section{ANTECEDENTES}

Se sabe que las modalidades son aquellas cláusulas que las partes introducen al acto o contrato para modificar los efectos normales de la obligación. Estas son, en general, el plazo, la condición y el modo.

Doctrinariamente el plazo es un hecho futuro e incierto del cual depende el ejercicio o la extinción de un derecho y su correlativa obligación. El plazo, como se sabe, tiene causales de extinción que están regulados principalmente en el Código Civil, y ellas son el vencimiento del mismo (lo que significa la llegada o su cumplimiento), la renuncia y, por último, su caducidad.

Es la caducidad el tema que está relacionado directamente con el análisis que se desarrollará acerca de la cláusula de aceleración en pagares con vencimientos sucesivos. La caducidad del plazo consiste en la extinción anticipada del mismo en los casos previstos por la convención o señalados por la ley. Es importante destacar que esta institución tiene por objeto proteger al acreedor cuando su crédito peligra por ciertas situaciones relacionadas con la solvencia del deudor que hacen temer que si se espera el vencimiento del plazo el acreedor no podrá cobrar en forma íntegra su crédito.

No es el tema de la caducidad legal el que concentrará nuestros esfuerzos en este comentario, sino el de la caducidad convencional, que se define como aquel que se produce en los casos expresamente previstos en el contrato, o sea, aquellos en que el acreedor se reserva el derecho a exigir anticipadamente el cumplimiento de todo o parte de la obligación en el evento de una condición. Una de las formas más usuales de esta caducidad convencional se encuentra en la estipulación de que el no pago oportuno de una, de varias cuotas, hará exigible la totalidad de la obligación, esto es lo que se denomina "cláusula de aceleración".

Profesor de Derecho Comercial, Universidad Católica del Norte (Chile). Licenciado en Derecho, Universidad Austral de Chile. Magíster en Derecho de la Empresa, Universidad del Desarrollo. LL. M. Queen Mary, University of London (Gran Bretaña), Correo electrónico: hcarrasco@ucn.cl

Fecha de recepción: 15 de marzo 2008.

Fecha de aprobación: 30 de julio de 2008. 


\section{Concepto de CLÁusula de ACEleración}

En este punto nos parece apropiado mencionar la definición que al respecto nos da Ubilla Grandi en su libro "La Cláusula de Aceleración en la obligación cambiaria", quien señala que "es un escrito puesto en una letra de cambio o en un pagaré, en virtud del cual ocurrido el o los hechos, futuros e inciertos, previstos en la cláusula, caduca o puede caducar el plazo suspensivo para el cumplimiento de la obligación, y el beneficiario de ella debe o puede -según la redacción imperativa o facultativa- exigir el cumplimiento cobrando antes de él o los vencimientos escritos en el documento"1.

La definición dada por el autor nos parece más apropiada atendido a que es mucho más amplia que el concepto que se puede desprender del artículo 105 inciso $2^{\circ}$ de la ley 18.092 .

\section{Tipos DE CLÁUSULAS DE ACELERACióN}

Como se puede derivar de la definición señalada, una cláusula de aceleración puede tener una redacción imperativa y otra facultativa.

Que esta cláusula tenga una redacción imperativa, significa que una vez que ocurre el hecho futuro e incierto para que se produzca la caducidad del plazo suspensivo, el beneficiario de ella debe exigir el cumplimiento antes del o los vencimientos escritos en el documento.

En cambio, la cláusula será facultativa cuando de su redacción se desprenda que no solo es necesaria la ocurrencia del hecho futuro e incierto para que caduque el plazo suspensivo para el cumplimiento de la obligación, sino que la exigencia del cumplimiento del o los vencimientos depende también de la voluntad del beneficiario.

El hecho de ser una cláusula facultativa o imperativa, puede tener distintas consecuencias que dependen obviamente de la facultad que tiene el beneficiario de acelerar el o los vencimientos pactados.

En todo caso, el objeto del presente comentario se centrará, principalmente, en la cláusula de aceleración facultativa debido al propio criterio del fallo que analizaremos. Sin embargo, antes de comenzar con el comentario propiamente tal, debemos hacer algunos cuestionamientos en relación a la cláusula de aceleración facultativa.

Ubilla Grandi, Luis (2008) La Cläusula de Aceleración en la obligación cambiaria, Santiago:

Editorial LexisNexis, 72 pp., p. 34. 


\section{Algunas Cuestiones Respecto de la CLÁUSULA DE ACELERACión FACULTATIVA}

En relación a este tema es abundante la jurisprudencia que se ha dictado, aunque no ha sido tan generoso el análisis doctrinario respecto del mismo. Especialmente importantes son las cuestiones que se relacionan con la prescripción de los pagarés que contienen las estipulaciones de aceleración, y que es necesario preguntarse lo siguiente:

a. ¿Desde cuándo se hace exigible la obligación?

b. ¿El instante en que se manifiesta la aceleración equivale al momento en que se hace exigible la obligación o son dos etapas diferentes?

c. ¿En qué momento se entiende que manifiesta la voluntad para acelerar la cláusula? ¿Al instante de presentar la demanda o de notificarla?

d. ¿Desde qué momento se cuenta la prescripción?

e. ¿Cuál es la doctrina que sigue nuestra Corte Suprema?

Todas estas preguntas son las que trataremos de esclarecer mediante el análisis del presente caso.

\section{El CASO}

El presente asunto se trata de un juicio ejecutivo de obligación de dar, caratulado "Banco Santiago con Manzano Dagoberto", rol 5384-1999, del $19^{\circ}$ Juzgado Civil de Santiago, que por resolución de 28 de junio de 2001, la jueza titular de dicho tribunal, acogió la excepción $17^{\text {a }}$ del artículo 464 del Código de Procedimiento Civil, esto es "la prescripción de la deuda o solo de la acción ejecutiva" opuesta a la ejecución, entre otras que si fueron rechazadas.

Esta sentencia fue apelada por la parte demandante y posteriormente revocada por una sala de la Corte de Apelaciones de Santiago (con fecha 21 de agosto de 2006), solo en cuanto acogió la petición subsidiaria del ejecutante (manifestada al evacuar el traslado de las excepciones y en el escrito de apelación), declarando la prescripción de las acciones cambiarias de aquellas cuotas del pagaré objeto de la ejecución cuya exigibilidad presentaba una antigüedad de un año o más a la fecha de notificación de la demanda, precisando que ello ocurría con las cuotas correspondientes a los meses de mayo a noviembre de 1999.

En contra de esta sentencia de segunda instancia la ejecutada dedujo recurso de casación en el fondo, el cual fue estimado por la Corte Suprema en causa Rol 5054/2006, como se verá.

La sentencia de segunda instancia sostenía para fundar su posición lo siguiente: 
1.- "Que, sobre la base de los hechos precedentes, particularmente aquel referido a la cláusula de aceleración acordada para el pago de la obligación, la sentencia impugnada discurre que pudiendo ser dicha cláusula redactada en términos imperativos o facultativos, esta última, como sería la de autos, otorga al acreedor el derecho de exigir el cumplimiento del documento completo, para lo cual debe manifestar su voluntad de acelerarlo, lo que normalmente, se practica, mediante la notificación de la demanda judicial $^{2}$, agregando que mientras ello no tenga lugar será como si la cláusula no se bubiere pactado, debiendo en tal evento cada cuota ser protestada separadamente, prescribiendo cada una de las acciones al cabo de un año desde su vencimiento, sin que la falta de pago de una o más cuotas produzca la caducidad del plazo, aunque el ejercicio tardío de dicha facultad no impediría la prescripción de las cuotas cuya exigibilidad se haya producido a más de un año antes de la notificación..."

2.- Que, la infracción de Derecho que se denuncia, se vincula con la forma de cómputo de la prescripción extintiva que alega el ejecutado al excepcionarse, el cual sostiene, previo reconocimiento de haber cesado efectivamente en el pago de la obligación que se persigue a contar del 12 de abril de 1999, que a la fecha de la notificación de la demanda, esto es, el 20 de noviembre de 2000 , había ya transcurrido el término o plazo de la prescripción, alegación que, por vía de revocación, se desestima en la sentencia impugnada, al sostenerse que la aceleración de la obligación, inicialmente dividida en cuotas, tuvo lugar precisamente con la notificación de la demanda. Consecuentemente con esta afirmación, entienden los jueces del fondo que antes de aquella notificación no ha comenzado a correr plazo o término alguno de prescripción, y ello, porque la voluntad de acelerar el crédito no ha podido tener lugar sino y con motivo de dicha notificación, pues sería esta la forma en que normalmente se practica la manifestación de voluntad, en orden a producir tal aceleración al amparo de la cláusula en cuestión".

En todo caso, esta sentencia de la Corte de Apelaciones de Santiago, encuentra apoyo también en otra resolución de la Corte Suprema de fecha 29 de junio del año 2006 (en autos caratulados "Carátula BANCO BIL-

Esta parece ser también la posición que sostiene el autor Ubilla Grandi (analizando el tema de que el ejercicio del derecho que confiere la cláusula de aceleración es la ejecución de un acto unilateral recepticio) al expresar que "Si bien concuerdo plenamente con lo que expresa el citado autor, podría irse un poco más allá, si se estima que aquí estamos frente a un caso típico de "Mora". No hay dudas que, conforme a las normas del derecho común, tratándose de la cuota vencida el deudor está en mora por el solo cumplimiento del plazo, pero no lo está respecto de las no vencidas mientras el acreedor no manifieste su voluntad en orden a cobrarlas anticipadamente activando la cláusula de aceleración, mora que solo se va a producir, conforme a las reglas del derecho común, con la notificación legal de la demanda y no con la sola presentación del libelo ni con ninguin otro acto de carácter extrajudicial". Ubilla (2008) 47. 


\section{BAO VIZCAYA ARGENTARIA C/ MEZA MALDONADO MILTON Y HENRIQUEZ VARGAS TAMARA" Rol 3438-2004)33.}

Por su parte, la Corte Suprema expresó las siguientes razones para revocar el fallo de segunda instancia:

"Que cualquiera sea el tenor, sentido y alcance que pueda o deba darse a la cláusula de aceleración en comentario, lo cierto es que de la forma razonada en la sentencia recurrida evidente resulta que se ha incurrido en el error de derecho que se reclama al apartarse los jueces de la instancia de lo prescrito por el legislador en el artículo 2514 inciso segundo del Código Civil, que ordena contar el plazo de prescripción extintiva a partir de que la obligación se hace exigible, cuestión de hecho que ocurre independientemente del acto de notificación de la demanda en que se persigue aceleradamente la obligación pactada en cuotas. En efecto, hacer pender el inicio del plazo de la prescripción a partir de tal circunstancia fáctica, exclusivamente dependiente de la sola voluntad del acreedor, transforma en los bechos, y contrariamente a derecho, en inaplicable el instituto de la prescripción ${ }^{4}$.

Lo anterior, independientemente del análisis acerca de si dicha actuación procesal de comunicación constituye o no una manifestación de voluntad

Esta sentencia señala en la parte relevante "Agrega la sentencia que las dos primeras cuotas convenidas en el pagaré se hicieron exigibles en las fechas estipuladas para cada una de ellas en dicho documento y que las restantes cincuenta y ocho -de un total de sesenta- vencieron todas el 30 de noviembre de 2003, fecha en que la demanda ejecutiva fue notificada a los demandados, manifestando el banco su voluntad de hacer efectiva la aceleración. Por consiguiente, concluye, de acuerdo al artículo 98, en relación al artículo 105, ambos de la Ley $\mathrm{N}^{\circ}$ 18.092, a la fecha de la notificación se encontraban prescritas solo las dos primeras cuotas," Areajuridica, http://www.areajuridica.cl:8800/mysite/jurisprudencia/comercial/folder.2004-12-15.8424111900/document.2006-07-20.0489952605[Fecha de visita 14 de julio de 20081.

4 Profundizando esta crítica Jara Cáceres, señala que "Esta teoría ha sido rechazada por parte importante de la doctrina y de la jurisprudencia, especialmente por la Excma. Corte Suprema, quienes se fundan principalmente en los siguientes argumentos:

i) Si la aceleración o exigibilidad anticipada de la obligación se produjera con la notificación de la demanda, se estaría confundiendo la prescripción propiamente tal con la interrupción de la misma.

ii) La prescripción, si se iniciara con la notificación de la demanda, nacería interrumpida, por lo que en la práctica no operaría esta institución, quedando en consecuencia la exigibilidad de la obligación al arbitrio del acreedor, burlando de esta manera las normas que establecen la prescripción, que son de Orden Público, y que por tanto escapan a la disponibilidad de las partes.

iii) Por último, los requisitos del título ejecutivo (Liquido, Actualmente Exigible y que no esté Prescrito), deben concurrir a la fecha de presentación de la demanda, época en la que, de no cumplirse, pondrán al juez en la necesidad de rechazar la demanda de plano." JARA CÁCERES, Javier (2006) "La cláusula de aceleración (o caducidad convencional del plazo)". Análisis Jurisprudencial http://www.areajuridica.cl:8800/mysite/revista/de-cara-al-derecho-una-columna-sobre-realidad-juridica/la-clausula-de-aceleracion-o-caducidad-convencional-del-plazo-analisis-jurisprudencial/?searchterm=aceleracion (fecha de visita 14 de julio de 2008). 
en orden a acelerar el cumplimiento de la obligación, cuestión de hecho que no forma parte del error de derecho que se denuncia".

En este sentido nos parece que la argumentación de la Corte goza de rigurosidad lógica y ello debido a que distingue certeramente el momento en que se hace exigible la obligación y aquel que se produce la manifestación de voluntad de acelerar el vencimiento de las cuotas pendientes. No debemos olvidar, además, que el artículo 105, inciso segundo, de la ley 18.092 , al referirse al pagaré con vencimientos sucesivos y cláusula de aceleración, dispone que para que se haga exigible "el monto total del saldo insoluto" debe producirse una condición y esta es "el no pago de una de las cuotas". De este tenor literal no se desprenden razones lógicas para establecer distintos momentos de exigibilidad de cada una de las cuotas del pagaré. Para fundamentar aun más esta posición, digamos que aquí cobra importancia el artículo 98 de la ley citada, que señala que la prescripción de un año esta se cuenta desde el "vencimiento del documento". A nuestro juicio, en el caso de manifestarse la voluntad de ejecutar la cláusula de aceleración (o incluso en el caso de una cláusula de aceleración imperativa), se estaría unificando el vencimiento de las cuotas a un solo momento, que en este caso coincide con el momento en que debió pagarse una cuota y esta no se hizo, o sea, desde que cae en mora. Entonces las expresiones "vencimiento" del art 98 de la ley 18.092 y "exigible" del artículo 2514 inciso segundo se hacen sinónimas.

En todo caso, el Tribunal supremo deja como una cuestión de hecho la circunstancia de determinar cuándo se produce la manifestación de voluntad en orden a acelerar los vencimientos posteriores de las cuotas. Sin embargo, en la sentencia de reemplazo la Corte estima que la voluntad de acelerar los vencimientos se produce con la interposición de la demanda. En efecto, se dispone " $1^{\circ}$.- Que la voluntad del acreedor en orden a acelerar el pago del crédito, originalmente pactado para ser servido en sesenta cuotas mensuales, se vio manifestada con la interposición de la demanda los días 19 y 26 de octubre de 1999, fechas en las que, respectivamente, se la ingresó a distribución por la Corte de Apelaciones y luego al tribunal a que fue asignada la causa..."

Se debe expresar que además de las tesis expuestas, existe una tesis intermedia que dispone que si la cláusula de aceleración está redactada en términos facultativos, la época de exigibilidad anticipada de la obligación se fijará al exteriorizarse la manifestación de voluntad en orden a acelerar el crédito y ello ocurre al momento de presentarse la demanda ${ }^{5}$. No esta-

En este sentido sentencia de la Corte Suprema de fecha 24 de Septiembre del año 2007, en autos caratulados "BANCO DE CHILE CON MACHIAVELO MARIANA, ROL 46342006. En Areajuridica.cl http://www.areajuridica.cl:8800/mysite/jurisprudencia/ comercial/folder.2004-12-15.8424111900/recurso-de-casacion-en-el-fondoacogido-comercial-juicio-ejecutivo-de-cobro-de-pagare-articulos-98-de-la-ley- 
mos de acuerdo con esta posición debido a que con ella se atenta contra el tenor del artículo 105 de la ley 18.092 que regula el pagaré con vencimientos sucesivos y con cláusula de aceleración.

De lo anterior parece desprenderse la conclusión de que no existe una jurisprudencia uniforme en esta materia. Entonces podríamos preguntarnos ¿por qué no ejercer la facultad que se consagra en el artículo $780^{6}$ del Código de Procedimiento Civil que permite uniformar los fallos diversos sobre una misma materia en la Corte Suprema?

El uso de esta facultad permitiría uniformar los distintos criterios que se han expresado y terminar con los problemas de certidumbre jurídica que derivan, principalmente, de la distinta composición de la primera sala de Corte Suprema ante el conocimiento de una causa.

En causa Rol N ${ }^{\circ}$ 574-2007 caratulada "BANCO SANTIAGO CON AMAR Y CIA. LTDA.", se solicitó por el recurrente, ante la dispersión jurisprudencial de la Primera Sala, que fuera el Pleno de la Corte Suprema el que conociera del recurso y se pronunciara sobre el mismo. La Suprema Corte accedió a la solicitud y en sentencia del 30 de enero de 2008, el pleno en voto de mayoría rechazó el recurso deducido por estimar que el recurrente no había cumplido con su obligación de establecer la influencia en lo dispositivo del fallo de la infracción de ley. Sin embargo, lo interesante de este fallo se vislumbra en que permite determinar cuál es el criterio seguido por los ministros de la primera sala de la Corte Suprema.

Sobre esta causa existe un interesantísimo análisis efectuado por el profesor José Luis Zabala Ortiz, en la revista "Leyes y sentencias", donde muestra cuáles son los criterios de los ministros de la Corte suprema y las contradicciones de algunos de ellos en diferentes fallos ${ }^{7}$.

nb0-18-092-2514-del-codigo-civil-y-471-del-codigo-de-procedimiento-civil-seencontraba-prescrita-la-accion/?searchterm $=4634 / 2006$ (Fecha de visita 14 de julio de 2008). También sentencia de esta misma Corte de fecha 30 de mayo del año 2007, en autos caratulados "BANCO SANTANDER CHILE CON SILVA CARVAJAL CRISTIAN A." ROL 5871/2005. En Areajuridica.cl http://www.areajuridica.cl:8800/mysite/jurisprudencia/ civil/folder.2004-12-15.9342344148-old/recurso-de-casacion-en-el-fondo-acogidojuicio-ejecutivo-infraccion-a-los-articulos-98-de-la-ley-18-092-y-464-no-17-delcodigo-de-procedimiento-civil/?searchterm =carla\%20salinas\%20cornejo (Fecha de visita 14 de julio de 2008).

6 Esta disposición consagra "Interpuesto el recurso de casación en el fondo, cualquiera de las partes podrá solicitar, dentro del plazo para hacerse parte en el tribunal ad quem, que el recurso sea conocido y resuelto por el pleno del tribunal. La petición solo podrá fundarse en el hecho que la Corte Suprema, en fallos diversos, ha sostenido distintas interpretaciones sobre la materia de derecho objeto del recurso."

Zabala Ortiz, José Luis (2008), "Oportunidad desde la que se cuenta el plazo de prescripción en pagaré con cláusula de aceleración facultativa para el acreedor. ¿Quedamos en lo mismo?”. Sección jurisprudencia comentada, Leyes \& Sentencias $N^{\circ} 57$. 


\section{CONCLUSIONES}

A nuestro juicio esta sentencia recoge la doctrina correcta en relación a cómo debe interpretarse la cláusula de aceleración (ya sea facultativa o imperativa), y de lo expuesto podemos dar las siguientes respuestas a las preguntas anteriormente planteadas:

\section{a. ¿Desde cuándo se hace exigible la obligación?}

En los pagarés con vencimientos sucesivos y con cláusula de aceleración (ya sea facultativa o imperativa), las cuotas que se anticipan se hacen exigibles desde el momento que se cumple la condición, esto es, desde la mora de la cuota respectiva.

No se arriba a la misma conclusión si se siguen aquellas doctrinas que hacen exigible anticipadamente la obligación, ya sea al momento de presentarse la demanda o al momento de notificarse la misma, porque para estas tesis se debe distinguir si la redacción de la cláusula es facultativa o imperativa. Si la cláusula es imperativa, la exigibilidad anticipada se produce en el momento de la mora en una de las cuotas, en cambio si es facultativa, esta se producirá, ya sea al momento de presentar la demanda o al momento de notificarla.

b. ¿El instante en que se manifiesta la aceleración equivale al momento en que se hace exigible la obligación o son dos etapas diferentes?

Para la tesis seguida en este trabajo son dos momentos distintos. La presentación de la demanda implica manifestación de la voluntad de acelerar los vencimientos y la notificación solo tiene por efecto, entre otros, el de interrumpir la prescripción.

La respuesta es distinta en las otras dos tesis, donde la manifestación de la aceleración equivale al momento de exigibilidad anticipada, variando solamente respecto de cuando se produce la manifestación.

c. ¿En qué momento se entiende que manifiesta la voluntad para acelerar la cláusula? ¿Al instante de presentar la demanda o de notificarla?

Como se pudo ver hay diversas posiciones, la sentencia de segunda instancia a que se hace referencia en el fallo analizado, entiende que al momento de notificarse la demanda. En cambio, como hemos visto y que constituye la doctrina correcta, esto se produce al interponerse la deman$\mathrm{da}^{8}$. Ello tiene importancia, especialmente en materia de abandono del procedimiento, ya que presentado a cobro un pagaré con vencimientos su- 
cesivos y cláusula de aceleración, si el juicio es declarado abandonado, se entiende que igual se manifestó la voluntad del acelerar los vencimientos futuros?.

\section{d. ¿Desde qué momento se cuenta la prescripción?}

De acuerdo a la tesis seguida por nosotros este plazo es uno solo, ya sea para la cláusula de aceleración facultativa o imperativa, y se contabiliza desde que se hace exigible la obligación, o sea, desde la mora de una de ellas.

En cambio, respecto de las otras tesis expuestas, el plazo comenzará a correr ya sea con la presentación de la demanda o con la notificación de la misma.

\section{e. Cuál es la doctrina que sigue nuestra Corte Suprema?}

Como se puede desprender de lo expresado, no existe claridad en esta materia y dependerá exclusivamente de la integración de la primera sala y de los abogados integrantes que se encuentren presentes.

Esperamos que se pueda ejercer nuevamente la facultad del artículo 780 del Código de Procedimiento Civil y así poder uniformar de una vez por todas la jurisprudencia de la Corte Suprema con el objeto de contribuir a uno de los fines del Derecho, cual es, la seguridad jurídica.

En este sentido, sentencia de la Corte Suprema, de fecha 20 de junio de 2006, en autos Caratulados "BANCO DEL ESTADO DE CHILE CON MANUFACTURAS DE HILOS E HILADOS RENAN S.A., Rol 1247-2004. En Areajuridica.cl http://www.areajuridica. $\mathrm{cl}: 8800 /$ mysite/jurisprudencia/comercial/folder.2004-12-15.8424111900/document.2006-06-21.0300805063 (Fecha de visita 14 de julio de 2008). 


\section{Corte Suprema \\ CAUSA ROL 5054/2006}

\section{VISTOS:}

Santiago, veintidós de octubre de dos mil siete.

En juicio ejecutivo de obligación de dar, caratulado "Banco Santiago con Manzano Dagoberto", rol 5384-1999, del $19^{\circ}$ Juzgado Civil de Santiago, por resolución de 28 de junio de 2001, la juez titular de dicho tribunal, acogió la excepción $17^{\mathrm{a}}$ del artículo 464 del Código de Procedimiento Civil, opuesta a la ejecución, entre otras, las que fueron rechazadas, decisión que apelada por la parte demandante fue revocada por una sala de la Corte de Apelaciones de Santiago con fecha 21 de agosto de 2006, solo en cuanto acogiendo la petición subsidiaria del ejecutante, manifestada al evacuar el traslado de las excepciones y en el escrito de apelación, declaró la prescripción de las acciones cambiarias de aquellas cuotas del pagaré objeto de la ejecución cuya exigibilidad presentaba una antigüedad de un año o más a la fecha de notificación de la demanda, precisando que ello ocurría con las cuotas correspondientes a los meses de mayo a noviembre de 1999. En contra de esta sentencia la ejecutada dedujo recurso de casación en el fondo que corre agregado a fojas 151 de estos autos.

Con la cuenta que ordena el artículo 782 del Código de Procedimiento Civil, se ordenó traer los autos en relación.

\section{CON LO RELACIONADO Y CONSIDERANDO:}

Primero: Que, el recurrente sostiene que la sentencia definitiva de segunda instancia incurre en infracción a los artículos 107, 98, 100 inciso primero, 105 incisos segundo y tercero, de la Ley 18.092, y 2518 del Código Civil, por no considerar debidamente la cláusula de aceleración contenida en el pagaré y confundir el acto jurídico modal que permite computar el término o plazo de prescripción.

Lo primero, atendidos los términos de la cláusula en cuestión, la que establece que se podrá hacer exigible al arbitrio exclusivo del Banco el pago total del capital adeudado o del saldo a que este se halle reducido, y sus intereses devengados, considerando la obligación como de plazo vencido, en caso de mora o simple retardo en el pago de una o más cuotas en que se divide la obligación, sean consecutivas o no. Conforme a esta, y con la presentación de la demanda el acreedor transformó la obligación en cuotas en obligación de plazo vencido, exigible en su totalidad, por lo que, 
estima el recurrente, atendida la fecha en que se practicó el requerimiento, debió confirmarse la sentencia de primera instancia.

Y lo segundo, porque debiendo contarse el término o plazo de la prescripción conforme al artículo 2514 inciso segundo del Código Civil, o sea, desde que la obligación se haya hecho exigible, lo que precisa la cláusula de aceleración en los términos antes transcritos, el fallo impugnado razona en forma contraria a derecho señalando que dicho plazo comienza a correr con la notificación de la correspondiente notificación (sic) de la demanda ejecutiva y aceleración del documento por parte del Banco acreedor. Dicha consideración viola los artículos 2518 incisos primero y tercero del Código Civil y 100 inciso primero de la Ley 18.092. En apoyo de lo anterior, cita y reproduce parcialmente tres sentencias de esta Corte, dictadas en autos caratulados "BHIF con Tello", de 14 de diciembre de 2005; "Banco de Chile con Weitzman y otro", de 11 de abril de 2001; y "Banco Estado con Silva", de 3 de mayo de 2006.

Los errores de derecho antes señalados han influido sustancialmente en lo dispositivo del fallo recurrido, por lo que pide se lo invalide y se dicte otra de reemplazo que "declare que se rechaza la demanda ejecutiva cabeza de autos, en todas sus partes, con costas".

Segundo: Que, en lo que importa al recurso constituyen hechos de la causa los que a continuación se indican: que el pagaré cuya ejecución se persigue fue suscrito el 13 de octubre de 1998; que para su pago se dividió la obligación en 60 cuotas mensuales; que el ejecutado cesó en el pago desde la cuota número 6 con vencimiento el 12 de abril de 1999; que la última cuota vencía el 13 de abril de 2003; que se pactó cláusula de aceleración; y que el ejecutado fue notificado y requerido de pago el 20 de noviembre de 2000.

Tercero: Que, sobre la base de los hechos precedentes, particularmente aquel referido a la cláusula de aceleración acordada para el pago de la obligación, la sentencia impugnada discurre que pudiendo ser dicha cláusula redactada en términos imperativos o facultativos, esta última "como sería la de autos" otorga al acreedor el derecho de exigir el cumplimiento del documento completo, para lo cual debe manifestar su voluntad de acelerarlo, lo que normalmente "se practica" mediante la notificación de la demanda judicial, agregando que mientras ello no tenga lugar será como si la cláusula no se hubiere pactado, debiendo en tal evento cada cuota ser protestada separadamente, prescribiendo cada una de las acciones al cabo de un año desde su vencimiento, sin que la falta de pago de una o más cuotas produzca la caducidad del plazo, aunque el ejercicio tardío de dicha facultad no impediría la prescripción de las cuotas cuya exigibilidad se haya producido a más de un año antes de la notificación.

En la especie, y sobre la base de haberse practicado el 20 de noviembre de 2000 la notificación de la demanda ejecutiva y su voluntad de acelerar el crédito, se decide que no es razonable considerar que todas las 
acciones cambiarias emanantes del pagaré se encontraban íntegramente prescritas, desechándose, en consecuencia, la prescripción total opuesta por el ejecutado acogiéndola en forma parcial como subsidiariamente lo pidiera la ejecutante.

Cuarto: Que, la infracción de derecho que se denuncia dice relación con la forma de cómputo de la prescripción extintiva que alega el ejecutado al excepcionarse, quien sostiene previo reconocimiento de haber cesado efectivamente en el pago de la obligación que se persigue a contar del 12 de abril de 1999 que a la fecha de notificación de la demanda, esto es, el 20 de noviembre de 2000, había ya transcurrido el término o plazo de la prescripción, alegación que, por vía de revocación, se desestima en la sentencia impugnada al sostenerse que la aceleración de la obligación, inicialmente dividida en cuotas, tuvo lugar precisamente con la notificación de la demanda. Consecuentemente con esta afirmación, entienden los jueces del fondo que antes de aquella notificación no ha comenzado a correr plazo o término alguno de prescripción, y ello, porque la voluntad de acelerar el crédito no ha podido tener lugar sino y con motivo de dicha notificación, pues sería esta la forma en que normalmente se practica la manifestación de voluntad en orden a producir tal aceleración al amparo de la cláusula en cuestión.

Quinto: Que cualquiera sea el tenor, sentido y alcance que pueda o deba darse a la cláusula de aceleración en comentario, lo cierto es que de la forma razonada en la sentencia recurrida evidente resulta que se ha incurrido en el error de derecho que se reclama al apartarse los jueces de la instancia de lo prescrito por el legislador en el artículo 2514 inciso segundo del Código Civil, que ordena contar el plazo de prescripción extintiva a partir de que la obligación se hace exigible, cuestión de hecho que ocurre independientemente del acto de notificación de la demanda en que se persigue aceleradamente la obligación pactada en cuotas. En efecto, hacer pender el inicio del plazo de la prescripción a partir de tal circunstancia fáctica exclusivamente dependiente de la sola voluntad del acreedor transforma en los hechos, y contrariamente a derecho, en inaplicable el instituto de la prescripción.

Lo anterior, independientemente del análisis acerca de si dicha actuación procesal de comunicación constituye o no una manifestación de voluntad en orden a acelerar el cumplimiento de la obligación, cuestión de hecho que no forma parte del error de derecho que se denuncia. Lo anterior, independientemente del análisis acerca de si dicha actuación procesal de comunicación constituye o no una manifestación de voluntad en orden a acelerar el cumplimiento de la obligación, cuestión de hecho que no forma parte del error de derecho que se denuncia.

Sexto: Que, en razón de lo expresado se concluye que la sentencia ha incurrido en infracción de ley constitutiva de un error de derecho que evidentemente ha tenido influencia en lo sustantivo del fallo recurrido, 
pues innegable resulta que al computarse el término de la prescripción de la manera que se hizo no podía sino, de acuerdo con los hechos de la causa, desestimarse la prescripción alegada. Por ello, se acogerá el recurso de casación de fondo interpuesto por la parte demandada, invalidándose la sentencia impugnada.

Por estas consideraciones y de conformidad, además, con lo dispuesto por los artículos 764, 765, 767 y 785 del Código de Procedimiento Civil, se acoge el recurso de casación de fondo, deducido por don José Luis Sotomayor, abogado de la parte demandada, en contra de la sentencia de veintiuno de agosto de dos mil seis, escrita a fojas 148 , la que se invalida y se reemplaza por la que se dicta a continuación, separadamente y sin nueva vista.

Regístrese.

Redacción a cargo del Ministro Sr. Milton Juica Arancibia.

Rol No 5054-2006

Pronunciado por la Primera Sala de la Corte Suprema, por los Ministros Sres. Milton Juica A., Sra. Margarita Herreros M., Sr. Kunsemüller y Abogados Integrantes Sr. Carrasco y Peralta.

No firma el Señor Carrasco, por no encontrarse en la Sala.

Autorizado por el Secretario Carlos A. Meneses Pizarro.

Santiago, veintidós de octubre de dos mil siete.

En cumplimiento de lo resuelto en el fallo de casación que antecede y lo que dispone el artículo 786 del Código de Procedimiento Civil, se procede a dictar sentencia que corresponde de conformidad con la ley.

\section{VISTO:}

Se reproduce el fallo en alzada.

Y se tiene además presente:

$1^{\circ}$. Que la voluntad del acreedor en orden a acelerar el pago del crédito, originalmente pactado para ser servido en sesenta cuotas mensuales, se vio manifestada con la interposición de la demanda los días 19 y 26 de octubre de 1999, fechas en las que, respectivamente, se la ingresó a distribución por la Corte de Apelaciones y luego al tribunal a que fue asignada la causa, libelo en el que además precisó, sin lugar a dudas, atento su tenor literal, que su intención era la cobrar el total del crédito adeudado en capital e intereses con motivo de la mora o retardo de la cuota número 6 , con vencimiento el 12 de abril de 1999, señalando que por tales conceptos 
el demandado le adeudaba $\$ 17.900 .919$.-, a la época de la mora o retardo antes indicada.

$2^{\circ}$. Que habiéndose hecho exigible la obligación, de la manera antes expresada a partir del 12 de abril de 1999 como quiera que fue esa la expresa voluntad del acreedor, al requerir ejecutivamente el pago del total adeudado en capital e intereses a esa fecha, es del caso que el curso de la prescripción que establece el artículo 98 de la Ley 18.092 para las acciones cambiarias que nacen del pagaré, no se vio interrumpido antes de completarse el plazo de un año que dicha norma fija, toda vez que la notificación de la demanda al ejecutado solo tuvo lugar el 20 de noviembre de 2000, esto es, después de transcurrido el término de prescripción que se menciona.

Se previene que el Ministro Sr. Juica, tuvo presente para confirmar el fallo en alzada únicamente que la cláusula de aceleración, sea facultativa o imperativamente pactada, no tiene ningún efecto con respecto de la exigibilidad de la obligación, puesto que esa norma solo contiene para el acreedor la facultad de transformar un crédito con vencimientos sucesivos en uno por el monto total insoluto, evitando con ello protestar y cobrar cada cuota de manera separada

Y visto además lo dispuesto en los artículos 186 y siguientes del Código de Procedimiento Civil, se confirma la resolución apelada de veintiocho de junio de dos mil uno, escrita a fojas 65 , con su rectificación o aclaración de diez de julio del mismo año, escrita a fojas 77 , debiendo en consecuencia cesar la ejecución, condenándose en costas a la parte ejecutante.

Redacción a cargo del Ministro Sr. Milton Juica Arancibia.

Regístrese y devuélvase, con sus agregados.

$\mathrm{N}^{\circ} 5054-2006$

Pronunciado por la Primera Sala de la Corte Suprema, por los Ministros Sres. Milton Juica A., Sra. Margarita Herreros M., Sr. Kunsemüller y Abogados Integrantes Sr. Carrasco y Peralta.

No firma el Señor Carrasco, por no encontrarse en la Sala.

Autorizado por el Secretario Carlos A. Meneses Pizarro. 